\title{
Toxicity of Smoke from Pelletized Leaf Powder and Essential Oil of Hyptis suaveolens (L.) Poit (Wild Spikenard) Against Anopheles gambiae (Giles, 1902) (Diptera; Culicidae)
}

\author{
Ajelara, K. O., " Denloye, A. A., Alafia, A. O., Awusinu, K., \\ Bajulaiye, A. A. and Muse, W. A. \\ Department of Zoology and Environmental Biology \\ Faculty of Science, Lagos State University, Ojo, Lagos
}

\begin{abstract}
Mosquitoes are the most important single group of insect vectors of the causative parasites of several diseases including malaria, dengue and filariasis for which cheap, safe, locally available and environmentally benign control measures are being sought. This study aimed at determining the toxicity of smoke from pelletized leaf powder and essential oil of Hyptis suaveolens (L) against third instar larvae and 0-2 day old adult Anopheles gambiae respectively in the laboratory. Test larvae were exposed to various concentrations ranging from $0 \mathrm{ppm}$ (control) through 50 to $500 \mathrm{ppm}$ of leaf essential oil at ambient laboratory temperature $\left(25 \pm 1{ }^{\circ} \mathrm{C}\right)$ in standard bioassay for $96 \mathrm{hrs}$ using Complete Randomized Block Design. Larval mortality was recorded at 24, 48, 72 and 96 hours of exposure. For exposure to pellets, 0-2 day old adult test insects were exposed to smoke from smoldering pellets having concentrations: $0 \%$ (Control), 20, 40, 60, 80 and 100\% in glass fumigation chamber where the test smoke and insects were contained. Data from quantal responses were subjected to Probit analyses for determination of lethal concentration values. Results showed that essential oil and smoke from smoldering pellet were toxic to both larvae and adults at all concentrations respectively. The computed $24 \mathrm{hr}-\mathrm{LC}_{50}$ of test essential oil against larvae is $1448 \mathrm{ppm} ; 48 \mathrm{hr}-\mathrm{LC}_{50} 551.47$ ppm, $72 \mathrm{hrs} \mathrm{LC}_{50}$ is $187.43 \mathrm{ppm}$ and 96 hours $\mathrm{LC}_{50}$ is $142.10 \mathrm{ppm}$, respectively. The insecticidal pellet $\mathrm{LC}_{50}$ at $30,60,90$ and 120 minutes values were $107.79 \%, 69.56 \%, 31.27 \%$ and $22.15 \%$, respectively. The results show that $H$. suaveolens could be exploited as a plant based insecticide for the control of Anopheles mosquitoes and suggests the need for further work including field studies.
\end{abstract}

Keywords: Anopheles gambiae, Hyptis suaveolens, Quantal response, Probit analysis, Biopesticide,

\section{INTRODUCTION}

There has been increased interest in exploring a wide diversity of plant natural products for use in the control of insect pests by researchers. Studies carried out have also focused on the

*Correspondence email: kemiteslim@yahoo.com determination of insecticidal potency and bioactivity of locally available plant species used as various formulations including powders, solvent (including ethanol, methanol, Petroleum ether) extracts, fixed oils, essential oils of leaves, stem bark, roots, fruits, seeds and so of the candidate plant species (Denloye et al., 2009; Oyewole, et al., 2010). Many of the 
plant species that form the focused of explorations have leveraged on the availability and uses of the plants by local communities (Ibidapo, 2005; Denloye, et al., 2009). Exploiting these local plant species may offer reliable alternatives to the synthetic insecticides widely acclaimed to contain noxious compounds that are toxic against humans and non-target species generally, expensive, not readily available and requiring complex technical know-how for their correct application. It is widely speculated that many local plants are yet to be explored for their insecticidal potency.

Among the plethora of plant species which are used against insects that have received little attention with attendant dearth of reports is the Wild Spikenad, Hyptis souaveolens L. (Poit) 1806. Like many plants of the world, $H$. suaveolens may have a rich store of phytochemicals that could be used in future control programs against mosquitoes and other insect pests of public health importance. Its leaf and branches are traditionally used as insect repellents (Lobani et al., 2011).

Mosquitoes have earned prominence over centuries for their nuisance value and vectorial capabilities in the transmission of deadly diseases including malaria, dengue fever, yellow fever, chikungunya, encephalitis, filariasis, and Zika Virus Disease (Fradin and Day, 2002). In Nigeria, Anopheles mosquitoes have become the focus of control strategies to break the transmission cycle of Malaria, just as it is globally done in the fight against the disease. The six primary vectors of malaria in Nigeria are Anopheles culicifacies, An. stephensi, An. fluviatilis, An. minimus, An. gyrus, and An. gambiae (Amajoh et al., 2002). These species are responsible for transmission in specific ecotypes, and of these; Anopheles culicifacies is squarely responsible for transmission of about $60-70 \%$ of the malaria in rural plains and peri-urban areas.

Mosquito control have often focused on the use of synthetic insecticides which are mostly complex toxic compounds with adverse impacts on non-target species; such as pesticide poisoning, bioaccumulation in fatty tissues and so on (National Resource Council, 1983; Kutz et al., 1991) the need for technical expertise and equipment for effective application and so on. These aftermaths of synthetic insecticides use against mosquitoes have become worrisome and therefore provoked the need for the use of environmentally safe, cheap, locally available and easy-to-use agents to achieve the control of these vectors. This need has generated interests in searching inwards for locally available plant materials to exploit as possible sources of the desired agents of the control of these mosquitoes and tackle the malaria scourge. There is a dearth of studies on the mosquitocidal activity of $H$. suaveolens, and the few available reports indicate palpable information gap that need to be closed for dependable conclusions on the possible insecticidal uses of $H$. suaveolens. Ivoke et al. (2009) assayed $H$. suavoelens against freshly laid eggs and larval instars of An. gambiae complex and reported that the test extracts significantly reduced egg viability and that they respectively demonstrated significant larval toxicity. Arivoli et al. (2011) evaluated H. suaveolens extracts for larvicidal, adult emergence inhibition and ovicidal activity against $A n$. stephensi and two other species of mosquitoes (Culex and Aedes). The study showed that $H$. suavoelens extracts had effective bioactivity against the insects and that An. stephensi was the least susceptible of the three test mosquito species. Also, Ayangae-Kaa et al (2015) reported that the dried leaf extract of $H$. suavoelens showed toxicity against the eggs of An. gambiae than it did to either the larvae or pupae, and thus emphasizing the ovicidal efficacy of $H$. suavoelens extract.

The foregoing highlights indicate that gaps exist in $H$. suavoelens insecticidal studies for example none of the studies has reported on the chemical constituents of $H$. suavoelens tested and 
no study has shown the efficacy of smoke from pellets of the dried leaves in Nigeria, but an earlier report by Denloye et al (2006) documenting the efficacy of smoke from the dried leaves of the Baobab tree (Adansonia digitata) had indicated the need to explore the use of smoke from pellets as insect control strategy. The present study was therefore, aimed at determining the toxicity of leaf essential oil vapour and pelletized dried leaves of $H$. suaveolens against adults or larvae of $A n$. gambiae under ambient laboratory conditions.

\section{MATERIALS AND METHODS}

\section{Preparation of Test Plant Materials}

Leaves of Hyptis suaveolens were obtained from Badagry area of Lagos State. The plant sample was identified at the herbarium of the Botany Department, University of Lagos by Dr Nodza with voucher number of LUH 8176. The leaves were plucked, rinsed under running tap water and air-dried on the laboratory bench at temperature of $27 \pm 1^{\circ} \mathrm{C}$ and $75 \%$ relative humidity for 10 days. The dried leaves were pulverized using Sonik ${ }^{\circledR}$ SB 1212 model electric blender and stored in air-tight container until when needed.

\section{Extraction of Test Essential oil}

Essential oil was extracted from $500 \mathrm{~g}$ pulverized Hyptis suaveolens leaves by hydrodistilation for 4-6 hours in a Clavenger apparatus (Kasali et al., 2006). The oil was collected over hexane and stored in the refrigerator at $4^{\circ} \mathrm{C}$ using amber airtight glass vials to prevent evaporation and ensure photo stability.

\section{Preparation of Pellets}

Insecticidal pellets were prepared from the test leaf powder blended with pulverized wood shavings using Renew ${ }^{\circledR}$ a common commercial laundry starch following the method of
Tawatsin et al (2002). Pellets were prepared by mixing $0.2 \mathrm{~g} \mathrm{H}$. suaveolens leaf powder with 0.8 g of pulverized wood shaving and $2 \mathrm{mls}$ of Renew ${ }^{\circledR}$ starch as a binder to make $20 \%$ concentration. The mixture was stirred for two minutes and moulded into 1.0 g pellet. The same procedure was used for all other test pellet concentrations namely 40, 60, 80 and 100\%. The control was prepared with $1.0 \mathrm{~g}$ of pulverized wood shaving and starch only.

\section{GC-MS Analysis of $\boldsymbol{H}$. suavoelens for Chemical Constituents}

The chemical constituents of test $H$. suavoelens essential oil was determined by means of Gas chromatograph/mass spectroscopy (GC/MS) following standard procedure previously described by Denloye et al (2009).

\section{Test Insects}

Anopheles gambiae sl eggs obtained from the insectary of Nigeria Institute of Medical Research (NIMR), Yaba, Lagos were incubated in the Pest Management Laboratory at Education Trust Fund (ETF) Building, Lagos State University were they hatched into larvae and subsequently used to raise a fresh stock culture of the test insect. The eggs were incubated in opaque glass cabinets and upon hatching they were maintained on plankton collected from with plankton net from the University Fish Hatchery. Adult males and females that emerged were maintained on $10 \%$ glucose solution and blood meal respectively from human volunteers who were given prophylatic antimalaria treatment two weeks before the experiments. The volunteers also gave their written consent before the commencement of the experiment.

Toxicity of Hyptis souaveolens pellet smoke against adult test Mosquitoes

Twenty (0-2 day old) adult An. gambiae sl were introduced into experimental laboratory glass chambered $(40 \times 40 \times 40 \mathrm{~cm})$ square cages. A 
$20 \%$ concentration pellet was ignited with lighter and mounted on a hanger inside the cage which was then covered to avoid the smoke escaping. The number of mosquitoes knocked down or dead was recorded at 30, 60, 90 and 120min of exposure. Mosquitoes found on the cage floor unable to fly but moving their legs, antennae or sany body part were counted as knocked down. Similarly, mosquitoes that were knocked down and unable to move any body part upon gentle prodding of the abdomen with a fine brush brittle were counted as dead and used for quantal response computations. The same procedure was used to set up similar experiments using $40,60,80$ or $100 \%$ pellets, respectively. In each case control was set up using pellets without $H$. suaveloens leaf powder. All experiments and control were made with four replicates, respectively.

\section{Toxicity of Hyptis suaovelens essential oil against $\boldsymbol{A n}$. gambiae larvae}

Stock solution of $H$. suaveolens essential oil was prepared with $1 \mathrm{ml}$ of the oil with $0.3 \mathrm{mls}$ of hexane in $100 \mathrm{mls}$ of water. The hexane in the mixture served as diluent to enhance miscibility of the essential oil in water. Serial dilutions of the stock solution were prepared to obtain 10, 50, 100, 200, 300, 400 and 500 ppm for larvicidal bioassay following the procedure of WHO (2005) For larvicidal assay 20 third instar larvae were introduced into each disposable transparent cup containing 10, 100, 200, 300, 400 and $500 \mathrm{ppm}$ of $H$. suaovelens essential oil. The control set up contained only distilled water and hexane in proportion 1000 $\mathrm{ml}$ to $0.3 \mathrm{ml}$, each experiment and control was replicated three times and arranged in Completely Randomized Block Design. Mortality was recorded after 24, 48, 72 and $96 \mathrm{hrs,}$ respectively. Larvae were considered dead when they floated, drowned or failed to move any part of their body with gentle swirling of the exposure cup.

\section{Data Analyses}

Analyses of dose response data on mortality of test mosquitoes was carried out using Environmental Protection Agency (EPA) Probit Analysis computer software following correction for mortality as a result of natural occurrence in control set up (Abbot, 1925, Finney, 1971). These analyses were used to compute Lethal Concentrations (LC) values and associated Confidence Limits (CL).

\section{RESULTS}

\section{Acute toxicity of Hyptis suaveolens against Third Instar larvae of Anopheles gambiae}

The computed Lethal Concentration (LC) values for the toxicity of $H$. suaveolens against An. gambiae are presented in Table 1. The essential oil extract was toxic to the larvae from concentrations 100 to $500 \mathrm{ppm}$ but not toxic at $50 \mathrm{ppm}$ as there was no mortality recorded at the lowest concentration tested.

\section{Toxicity of Hyptis suaveolens against adult Anopheles gambiae sl}

Toxicity test showed that $H$. suaveolens pellet smoke was toxic against adult Anopheles gambiae. The computed $\mathrm{LC}_{50}$ values of the smouldering pellet against the test insect at 30 mins exposure time was $107.79 \mathrm{ppm}$ while it was $22.15 \mathrm{ppm}$ at 120 mins. Comparison between the $\mathrm{LC}_{50}$ values at 30 and 60 mins exposure gave no significant difference as shown by overlap in the computed Confidence Limits (Table 2).

\section{Chemical Constituents of Test Hyptis suavoelens leaf Essential Oil}

Gas Chromatography Mass Spectroscopy (GCMS) analysis gave chromatograph which revealed peaks depicting 13 major compounds in the test essential oil (Figure 1). These peaks 
Table 1: Toxicity of Hyptis suaveolens leaf essential oil against third Instar Larvae of Anopheles gambiae.

\begin{tabular}{llllll}
\hline $\begin{array}{l}\text { Exposure Time } \\
(\mathrm{hr})\end{array}$ & $\begin{array}{l}\mathrm{LC}_{50} \\
(\mathrm{ppm})\end{array}$ & $\begin{array}{l}\text { 95\% Confidence } \\
\text { Limits }\end{array}$ & Slope & $\begin{array}{l}\text { Degree of } \\
\text { Freedom }\end{array}$ & Chi-square \\
\hline 24 & 1448.27 & $565.09-1580$ & $0.899 \pm 0.652$ & 3 & 3.16 \\
48 & 551.47 & $\mathrm{NE}$ & $1.064 \pm 0.654$ & 3 & 6.87 \\
72 & 187.43 & $16.61-454.18$ & $1.052 \pm 0.652$ & 3 & 1.23 \\
96 & 142.10 & $57.28-213.63$ & $1.387 \pm 0.662$ & 3 & 1.23 \\
\hline
\end{tabular}

ppm $=$ Parts per million

$\mathrm{NE}=$ Not Estimable, slope not significantly different from 0 .

$\mathrm{SE}=$ Standard Error

Table 2. Toxicity of Hyptis suaveolens pellets smoke against adult An. gambiae

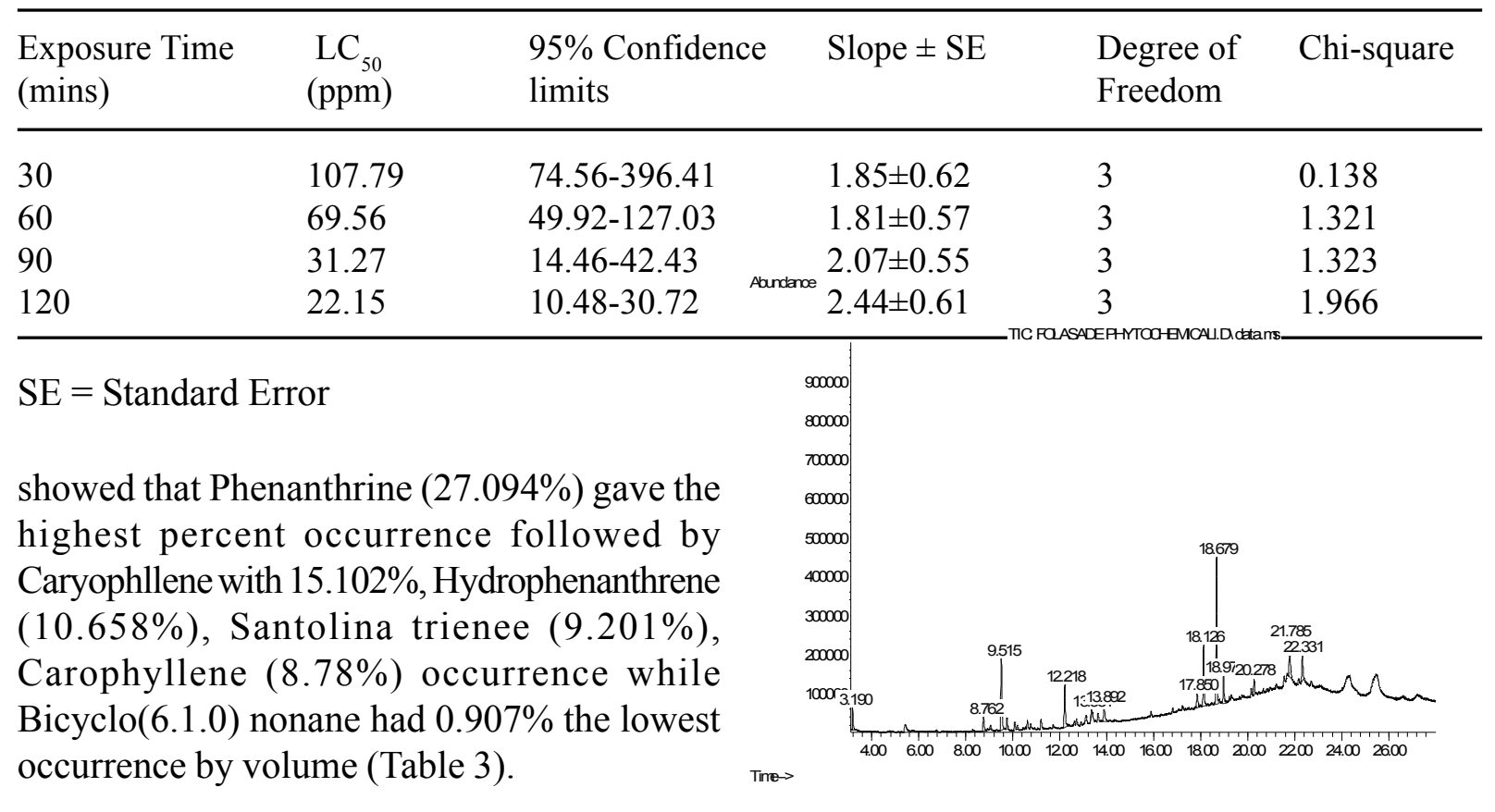

Fig. 1: Chromatograph from GC/MS Analysis of leaf essential oil of Hyptis suaveolens 
Table 3: Chemical Constituents of the leaf Essential oil of Hyptis suaveolens with their percent composition

\begin{tabular}{lll}
\hline SN & Compounds & $\begin{array}{l}\text { \% Compo- } \\
\text { sition }\end{array}$ \\
\hline 1 & Oxime-,methoxy-phenyl- & 2.87 \\
2. & Alpha.-cubebene & 3.215 \\
3. & Caryophllene & 15.102 \\
4. & Santolinatrienee & 9.201 \\
5. & Bicyclo(6.1.0) nonane, & 0.907 \\
& 9-(1-methyle & \\
6. & Bergamotol,Z-alpha-trans- & 4.894 \\
7. & 3.beta.,17 dihydroxyestr-4-e & 3.344 \\
8. & Hydrophenantherene & 10.658 \\
9. & Phenanthrene & 27.094 \\
10. & 4"a-Methyl-8"-methylidene- & 5.317 \\
& decahy & \\
11. & Diazoprogesterone & 2.878 \\
12. & Caryophyllene & 8.878 \\
13. & Heptadeca-1,9-dien-4,6-diyn & 5.643 \\
\hline
\end{tabular}

\section{DISCUSSION}

Hyptis suaveolens extracts have been shown to have effect on target insects at various stages of their development as demonstrated by Ayange-Kaa et al (2015) who worked on effect of dried leaves of Hyptis suaveolens on egg, larvae, pupa and adult mosquito and discovered that that the eggs showed highest mortality to Hyptis suaveolens extracts. The work is equally in line Bobbo et al (2016) who assessed the larvicidal activity $H$. suaveolens and Balanites aegyptiaca leaves and root extract against mosquito species and discovered that both plants were toxic to mosquito species at all concentrations. The plant equally showed high toxicity to Anopheles stephensi and Culex quinquifascatus in hexane extract as shown by Arvoli and Tennyson (2011). The same way this present study demonstrated the toxicity of $H$. suaovelens essential oil and pellets against third instar larvae and 0-2 day old adult $A n$. gambiae have been demonstrated in this study.
The result showed that $H$. suaovelens was effective against the test mosquito species in line with reports received from rural dwellers in Badagry area of Lagos State as opposed to mere adherence to traditional practice or folklore. This throws more light on the study reported by Egunyomi et al. (2010) that studied 10 popularly used mosquito repellents in Ibadan, Nigeria.

The present study agrees with findings of Conti et al (2012) who worked on larvicidal and repellent activity of $H$. suaveolens essential oil against Aedes albopictus and discovered that essential oil of $H$. suaveolens had a significant repellent activity and could confer 16 to 135 minutes protection against biting mosquitoes with differences in repellency rates being a function of concentration and time of observation. While larvae mortality range is between 93.33 and $98.33 \%$. same efficacy was also reported by Murugesan et al. (2015) reported that leaf extracts of $H$. suaveolens to be highly effective to larvae of Culex quinquefasciatus. Also, Govindaraja et al. (2012) reported strong larvicidal effect of $H$. suavoelens against the same species. The foregoing therefore support the findings in this study.

Equally effect of pellets and plant based coils have shown to be similar in their mode of action; this have been demonstrated by Tawatsin et al (2002); since pellets and coils are among the most common household insecticide products used for personal protection against mosquitoes and other biting dipterans.

The larvicidal and repellency of $H$. suavoeloens in this study may be due to the activity of the chemical constituents of the test plant species. The chemical constituents obtained by GC/MS analysis in this study are comparable to those reported by earlier workers such as Benelli et al (2012) who reported 50 compounds found in $H$. suavoelens from 
Burkina Faso and Chatri et al (2014) that also reported 50 compounds from Indonesia. The differences in number of compounds may be due to ecotype variations since the plant materials used in this study were not sourced from the same locations as the earlier studies by Syamasundar et al (2012) who showed variations in volatile oil composition of different wild collections of Hyptis suaveolens from Western Ghats of India and discovered that the essential oils showed considerable significant differences in their compositions due to areas of collection. The same was also observed by Lohani et al (2011) who worked on variations in essential oil composition and biological activity of $H$. suaveolens from two sites; Raniphokari and Mohand area of India. It is therefore imperative for further studies on the chemical analysis of the plant's oil extract, insecticidal activities and its mode of action.

In conclusion, this study makes obvious the potential of $H$. suavoelens as a mosquito control agent for rural dwellers of Badagry LGA, Lagos, Nigeria. Further studies be carried out to determine the constituent of $H$. suavoelens that possess mosquitocidal properties for further exploitation.

\section{REFERENCES}

Abbott W.S (1925). A method of computing the effectiveness of an insecticide. $J$ Econ Entomol., 18:265-267.

Amajoh, C.N., Oduoko, J.B. and Mosanya, M.E. (2002). Preliminary investigations on malaria in Antlantic Coastal Margin of Ibeju-Lekki, Lagos State, Nigeria. Journal of Malaria in Africa and the Tropics, 1:17-19.

Arivoli, S. and Tennyson, S. (2011). Mosquitocidal Activity of Hyptis suaveolens (L.) Poit (Lamiaceae) Extracts Against Aedes aegypti, Anopheles stephensi and Culex quinquefasciatus (Diptera: Culicidae). International Journal of Recent Scientific Research, Vol. 2(5): 143-149.
Ayange-kaa, A.B., Hemen, T.J. and Onyezili, N. (2015). The Effect of Dried Leaves Extract of Hyptis suaveolens on Various Stages of Mosquito Development in Benue State, Nigeria. IOSR Journal of Pharmacy and Biological Sciences, 10(6): 28-32.

Benelli, G., Flamini, G., Canale A., Molfetta, I., Cioni, P.L. and Conti, B. (2012). Repellence of Hyptissuaveolens Whole Essential Oil And Major Constituents Against Adults of TheGranary Weevil, Sitophilus granarius. Bulletin of Insectology, 65(2): 177-183.

Bobbo, A. A., Pukum, M. S. and Qadeer, M. A. (2016). Assessment of Larvicidal Activity of Hyptis suaveolens and Balanites aegyptiaca Leaves and Root Extracts against Mosquito Species. International Journal of Scientific and Research Publications, Volume 6, Issue 3: 10-14.

Chatri, M., Baktiar, A. M. and Adnadi, P. (2014). Chemical Constituents of Essential oil of Leaves of Hyptis suaveolens (L) Poit from Indonesia. American Journal of Research Communication, 2(10): 30-38.

Conti, B., Benelli, G., Flamini G., Cioni, P.E., Ceccarini, L., Mcchia, $M$ and Canale, $A$. (2012). Larvicidal and repellent activity of Hyptis suaveolens (Lamiaceae) essential oil against the mosquito Aedes albopictus Skuse (Diptera: Culicidae). Parasitology Research, 110:(5) 2013-2021.

Denloye, A. A. B., Teslim, K. O. and Fasasi, A. O. (2006). Insecticidal and repellency effects of smoke from plant pellets with or without D-allethrin 90 EC against three medical insects. Journal of Entomology, 30: 1-5.

Denloye, A. A., Oluwakemi K. A., Rasak, A. O., Eshilokun, A. and Makanjuola, W. A. (2009). Insecticidal activity of petroleum ether extract and essential oil of Chenopodium ambrosioides L. (Chenopodiaceae) against Anopheles gambiae (Diptera; Culicidae). Acta Entomologica Sinica, 52(8): 923-928.

Egunyomi, A., Gbadamosi, I.T. and Osiname, K.O. (2010). Comparative Effectiveness of Ethnobotanical Mosquito Repellent used in 
Ibadan, Nigeria. Journal of Applied Biosciences, 36: 2383-2388.

Finney, D. J. (1971). Probit Analysis. 3rd ed. Cambridge University Press, London.

Fradin, M.S. and Day, J.F. (2002). Comparative Efficacy of Insect Repellent Against Mosquito Bites. New England Journal of Medical, 347: 13-18.

Govindarajan, M., Sivakumar, R., Amsath, A. and Niraimathi S. (2012). Larvicidal efficacy of botanical extracts against two important vector mosquitoes. Journal of Pharmaco-logical Science, 16 (3): 386-92.

Ibidapo, C. A. (2005). Perception of Causes of Malaria and Treatment Seeking Behavior of Nursing Mothers In A Rural Community. Australian Journal of Rural Health, 13(4): 214-218.

Ivoke, N., Okafor, F. C. and Owoicho, L. O. (2009). Evaluation of Ovicidal and Larvicidal Effects Of Leaf Extracts of Hyptis Suaveolens (L) Poit (Lamiaceae) Against Anopheles gambiae (Diptera: Anophelidae) Complex. Animal Research International, 6(3): 10721076.

Lohani, H., Andola, H.C. and Chauhan, N. (2011). Variations in essential oil composition and biological activity of Hyptis suaveolens Poit: A high value aromatic plant of the Himalaya. Medicinal Plants, 3(4): 1-4.

Kasali, A.A, Ekundayo, O., Paul, C., Konig, W.A., Eshinlokun, A.O. and Ige, B. (2006). 1,2,3,4 Diepoxy-P-menthane and 1,4-epoxyp-menth-2-ene; Rare monoterpernoids from the essential oil of Chenopodium ambrosoides L. Journal of Essential oil Research, 18 (1): 13-15.

Kutz, F.W., Wood, P.H and Boltimore, D.P (1991). Organochlorine Pesticides in and Polychlorinated biphenyls in human adipose tissues. Review of Enviromental Contaminants and Toxicology, 120: 1-82.

Murugesan, S., Palani, G., Murugesan, S., Subramanian, A., Rajasingh, R. and Samuel, T. (2015). Larvicidal Activity of Hyptis Suaveolens (L.) Poit (Lamiaceae) Aerial Extracts Against TheFilarial Vector Culex quinquefasciatus Say (Diptera: Culicidae) Journal of Medical Parasithology Science, 3(4): 01-05.

National Resource Council (1983). Pesticides in the Diets of Infants and Children. National Academy Press Washington DC.

Oyewole, I. O., Moronkola, D. O, Oguwande, I. A., Okoh, B., Ibidapo, C. A., Denloye, A. A. B.,Ogunnowo, A. A. and Adedayo, N. (2010). Larvicial activity of the essential oil from Phyllanthus amarus Sch. et Thonn (Euphorbiaceae) against three species mosquitoes. Der Phnarcia Lettre, 2(6): 136141.

Syamasundar, K.V., Vinodh,G., G.V., Srikanth, S. and Balakishan, B. (2012). Variations in Volatile oil Compositions of Different wild Collections of Hyptis suaveolens (L) PoitfFrom Western Ghats of India. Journal of Pharmacognosy, 3(2): 131-134.

Tawatsin. A., Thavara, U. and Chompoosri. J. (2002). Field Evaluation of Mosquito Coils Derived from Plants againstNight-Biting Mosquitoes in Thailand. National Institute of Health, Department of Medical Sciences, Ministry of Public Health. Published in Proceedings International Conference on Biopesticides, 3, April 21-26, 2002, Kuala Lumpur, Malaysia, 214-220.

World Health Organisation. (2005). Guidelines for Testing of Mosquito Larvicides.WHO/ CDS/WHOPES/GCDPP. No. 13.
Nigeria Journal of Entomology

Published by the Entomological Society of Nigeria

www.esnjournal.com.ng

ISSN: 0331-0094

Vol. 34, 2018; pp. 61-68

DOI: $10.36108 / N J E / 8102 / 43(0170)$

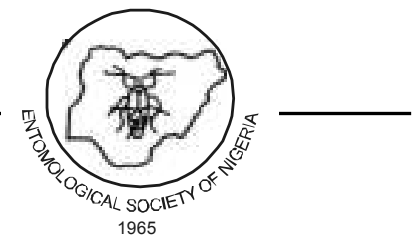

